\title{
New and emerging contraceptive options: a focus on transdermal contraception
}

This article was published in the following Dove Press journal:

Open Access Journal of Contraception

8 January 2014

Number of times this article has been viewed

\section{Bettina Böttcher Ludwig Wildt}

Department of Gynecologic Endocrinology and Reproductive Medicine, Innsbruck Medical University, Innsbruck, Austria
Correspondence: Bettina Böttcher Department of Gynecologic Endocrinology and Reproductive Medicine, Innsbruck Medical University, Anichstrasse 35, A-6020 Innsbruck, Austria

Tel +435I250423276

Email bettina.boettcher@i-med.ac.at
Abstract: Transdermal contraception is a convenient way of hormonal contraception that allows weekly application of a patch for 3 consecutive weeks followed by a patch-free week. Efficacy, side effects, advantages, and disadvantages as well as patient satisfaction with this formulation are discussed in this short review. The first patch, introduced in 2002, contained ethinylestradiol and norelgestromin. Recently, a new patch containing gestodene as the gestagen component has been developed. Early data for this formulation are presented.

Keywords: transdermal contraception, skin patch

\section{Introduction}

Combined hormonal contraception is widely used by women of reproductive age. Different delivery methods, apart from the oral regime, have been introduced in recent years, including the vaginal ring and the transdermal patch. Low molecular weight and high lipophilicity are the main conditions needed for a drug to be able to be delivered via the transdermal route. ${ }^{1,2}$ Patches for hormone replacement therapy were introduced several years ago.

\section{Safety and efficacy}

The first patch designed for hormonal contraception contained ethinylestradiol and norelgestromin. A dose-finding study in 610 women demonstrated that the amount of estrogen and gestagen delivered by a $20 \mathrm{~cm}^{2}$ patch was capable of suppressing ovulation and maintaining adequate cycle control. ${ }^{3}$ Weekly administration for 3 consecutive weeks followed by a week without a patch provides contraceptive safety and regular menstruation. In addition, non-oral application and weekly intervals improve compliance.

The Pearl Index has been assessed in several studies. One randomized study of 1,417 women comparing a combined oral contraceptive with the patch reported a similar Pearl Index in both groups. ${ }^{4}$ In another study, the overall Pearl Index was 0.88 for women using the patch and 0.56 for women using oral contraceptives containing desogestrel. ${ }^{5}$

In contrast with oral contraceptives, vomiting and diarrhea do not interfere with contraceptive efficacy when a transdermal patch is used. Women with lactose intolerance can also benefit from the transdermal route of application. The patch can be placed on different sites of the body because serum concentrations of norelgestromin and ethinylestradiol do not differ in relation to site of application. ${ }^{6}$ 


\section{Metabolism and risk of venous thromboembolism}

Due to its different pharmacokinetic profile, side effects might be reduced with the patch, as it avoids the high peak concentration found with daily oral application and maintains constant drug levels. ${ }^{7}$ A comparison of oral and transdermal administration of ethinylestradiol in 41 hysterectomized women showed an absence of first-pass effects on hepatic function. In this study, lipid profiles were affected by oral administration of ethinylestradiol but not by transdermal administration. ${ }^{8}$ However, a crossover study examining liver proteins in patients with either vaginal or oral delivery of ethinylestradiol showed no significant differences in this respect. It was therefore stated that changes in these proteins were independent of the delivery route ${ }^{9}$ and did not depend on first-pass delivery to the liver. This may be explained by the fact that the area under the curve for ethinylestradiol concentration after transdermal administration is higher than that found for the oral route of delivery.

Similar findings were reported by van den Heuvel et al, ie, ethinylestradiol levels were significantly higher in patients receiving the patch than in those taking the contraceptive pill or using the vagina ring. ${ }^{10}$ Therefore, the US Food and Drug Administration issued a warning in 2005 that higher ethinylestradiol levels in patch users might be accompanied by a higher risk of venous thromboembolism. Indeed, a two-fold greater risk for venous thromboembolism has been reported for users of the patch as compared with women using oral contraceptives containing 30-35 $\mu \mathrm{g}$ of ethinylestradiol and norgestimate or levonorgestrel. Similar findings have been reported by some but not all investigators. ${ }^{11-14}$

In a recent analysis of pooled data, the relative risk of thrombotic events was calculated for an oral contraceptive with drospirenone, the patch with norelgestromin, and the vaginal ring with etonogestrel. No statistically significant association with prevalence of venous or arterial thrombotic events was found for the patch or the ring. ${ }^{15}$

It is obvious that the patch should not be prescribed to patients with a history of or predisposition to venous thromboembolism, acute myocardial infarction, or ischemic stroke. All relevant risk factors should be assessed and discussed with all women. ${ }^{2}$

\section{Side effects}

Typical side effects are headache (21.9\%), nausea (20.4\%), application site reactions (20.2\%), and breast discomfort (18.7\%). These adverse reactions were identified in a study evaluating the efficacy and safety of the patch in 812 users. $^{4}$ Similar results were found in other studies. ${ }^{2,10,16}$

In a randomized parallel-group study, adverse events such as nausea and breast tenderness were more frequent in patch users than in pill and ring users. ${ }^{10}$ Breakthrough bleeding occurred more often in the first two cycles when comparing patch versus pill users. However, after six or 13 cycles, breakthrough bleeding and spotting rates were similar. Compliance was slightly better in patients using the patch than in those using an oral contraceptive $(88.2 \%$ versus $77.7 \%$, respectively). In the same study, $1.8 \%$ of patches completely detached and another $2.8 \%$ showed partial detachment. ${ }^{4}$ Once the patch has been removed, it cannot be reapplied. ${ }^{2}$

Dysmenorrhea was shown to be more frequent in patch users than in oral contraceptive users (13.3 versus $9.6 \%$, respectively). ${ }^{16}$ In the same study, body weight changes were compared between users of triphasic oral contraceptives and the patch with norelgestromin. A similar weight gain of $0.3 \mathrm{~kg}$ was shown. Overall, apart from skin reactions, side effects were comparable with those of combined oral contraceptives. ${ }^{17}$

In a study examining the pharmacokinetics and adhesion of a transdermal contraceptive patch containing levonorgestrel, it was found that serum drug levels remained stable even when patients went to the sauna, to the whirlpool, or undertook treadmill exercises. Patch adhesion under these circumstances was satisfactory. ${ }^{18}$

The effect of transdermal contraception on bone density has been discussed in the past. A systematic literature review found no negative influence on bone mineral density, although stated that data are very limited for the skin patch. ${ }^{19}$ A randomized study examined 20 women using the patch containing $20 \mu \mathrm{g}$ of ethinylestradiol and $150 \mu \mathrm{g}$ of norelgestromin and 20 women using the vaginal ring, with 20 women without hormonal contraception serving as healthy controls. Parameters for bone turnover were measured every 3 months for one year, and bone mineral density was measured by dual energy $\mathrm{X}$-ray absorptiometry at baseline and after 12 months. No significant differences in spinal bone mineral density were found. Biochemical markers of bone resorption were significantly reduced in the contraception groups compared with the control group. The authors concluded that there was no negative impact of the patch or vaginal ring on bone metabolism or bone mineral density. ${ }^{20}$ These results are in accordance with an earlier study by Harel et al which reported no significant differences in bone mineral density, even in adolescents who had been using the patch for 12 months. ${ }^{21}$ 
The effect of obesity on the efficacy of the transdermal route of application has been discussed in the past. A recent study examined ovarian follicular suppression in women with a body mass index $>30$ compared with women with a body mass index $<30$ using patches containing three different doses of ethinylestradiol and levonorgestrel. Ovarian activity in the luteal phase was suppressed in both groups. ${ }^{22}$ However, in an analysis of pooled data, a significant association between contraceptive failure and body weight $>90 \mathrm{~kg}$ was shown. ${ }^{23}$

\section{Patient satisfaction}

Patient satisfaction and compliance were significantly better with the patch than with an oral contraceptive in a parallelgroup study of 846 women using the patch and 643 patients using the pill. ${ }^{5}$ Side effects were comparable with those reported by Audet et al. ${ }^{4} \mathrm{Cycles}$ with perfect compliance were significantly more common in patch users $(P<0.001){ }^{5}$

Although patient satisfaction with the patch is good, it is still not a well-known or widely used contraceptive method. This may be the result of inadequate counseling. A study of 18,787 women demonstrated that patch use increased significantly after counseling about the different contraception options. ${ }^{24}$ In a multinational study over 6 months, a high level of satisfaction and compliance was reported for patch users. Over $80 \%$ of 778 users were satisfied with this method, and after four cycles of transdermal contraception, $73.7 \%$ preferred the patch to their previous contraceptive regimen. ${ }^{25}$

\section{Extended cycle}

The extended cycle, well established for combined oral contraceptives, has been examined with the patch as well. Weekly application was performed for 12 consecutive weeks followed by a patch-free week compared with the 3-week application regimen. Bleeding episodes and number of bleeding days were less frequent with the extended regime. ${ }^{26}$

\section{New patch containing ethinylestradiol and gestodene}

Most of the studies cited above refer to the transdermal patch containing ethinylestradiol and norelgestromin. A new patch containing a different gestagen has been developed. Gestodene belongs to the group of third-generation gestagens. It has been used frequently in combined oral contraceptives and has therefore been chosen as the gestagen part of the patch. The patch containing gestodene is half the size of the common patch containing norelgestromin. It measures only $10 \mathrm{~cm}^{2}$, and contains $0.9 \mathrm{mg}$ of ethinylestradiol and $1.9 \mathrm{mg}$ of gestodene in a polyisobutylene matrix which is one of five layers. ${ }^{27}$ The first efficacy results with regard to suppression of ovulation were obtained over two menstrual cycles in a twocenter study with 199 volunteers. ${ }^{27}$ The patch was attached for 3 consecutive weeks, followed by a patch-free week. Using transvaginal ultrasound sonography and measuring hormone levels, it was shown that ovulation was suppressed in all subjects. After these two cycles, ovulation returned in $85.7 \%$ of the patients. The patch was well tolerated. Another advantage of the new patch containing gestodene is its color. The well-established patch is beige whereas the new patch is transparent and therefore easier to hide.

Safety aspects were also examined in the abovementioned study. ${ }^{27}$ Rash was reported in $22.6 \%$ of patients, breast pain in $15.6 \%$, and headache in $7.5 \%$. All adverse effects resolved spontaneously. Problems with adhesion, especially after visiting the sauna or swimming, for example, were reported. Laboratory safety measurements were stable, ${ }^{27}$ and the duration of withdrawal bleeding was reduced.

In a recent study by Junge et al, ${ }^{28}$ surrogate parameters for risk of venous thromboembolism were examined for a patch containing $0.55 \mathrm{mg}$ of ethinylestradiol and $2.1 \mathrm{mg}$ of gestodene. This was compared with an oral contraceptive pill containing $0.03 \mathrm{mg}$ of ethinylestradiol and $0.15 \mathrm{mg}$ of levonorgestrel. Unfortunately, it was not explained why the dose of the patch was different from the one described previously. Prothrombin fragments and D-dimer values were used as prothrombotic markers and measured in 30 volunteers who received the patch and the oral contraceptive for three cycles each, with a washout period in between. Comparable effects on these parameters were shown for the two different regimens of contraception. Prothrombin fragments were stable during the first cycle but increased during the second cycle. D-dimer values increased in both cycles, and with no significant difference comparing the groups. However, risk assessment for venous thromboembolic events will need to await the outcome of large prospective studies.

Regarding secondary parameters, withdrawal bleeding occurred in $86.7 \%-100 \%$ of the women. In total, $72.4 \%$ of patch users and $62.1 \%$ of oral contraceptive users reported adverse events, 12 of which were treatment-related. Compliance in both groups was excellent. ${ }^{28}$

Another pharmacological system, ie, a double-layer matrix releasing gestodene and ethinylestradiol steadily over one week, was introduced in $2009 .^{29}$

Overall, transdermal contraception can be offered as a safe, efficient, and convenient method of contraception. However, at present, distinct medical advantages in comparison with 
other contraceptives are not evident. Moreover, the reported increase in risk for venous thromboembolism in some studies may be of concern.

The choice of drug administration is not only determined by pharmacokinetic and pharmacological data but also by the preferences of women using contraceptive products, and as such, is influenced by age, lifestyle considerations, and last but not least, by marketing strategies.

\section{Disclosure}

The authors report no conflicts of interest in this work.

\section{References}

1. Graziottin A. Safety, efficacy and patient acceptability of the combined estrogen and progestin transdermal contraceptive patch: a review. Patient Prefer Adherence. 2008;2:357-367.

2. Burkman RT. Transdermal hormonal contraception: benefits and risks. Am J Obstet Gynecol. 2007;197(2):134. e1-e6.

3. Dittrich R, Parker L, Rosen JB, et al. Transdermal contraception: evaluation of three transdermal norelgestromin/ethinyl estradiol doses in a randomized, multicenter, dose-response study. Am J Obstet Gynecol. 2002;186(1):15-20.

4. Audet MC, Moreau M, Koltun WD, et al. Evaluation of contraceptive efficacy and cycle control of a transdermal contraceptive patch vs an oral contraceptive: a randomized controlled trial. JAMA. 2001;285(18): 2347-2354.

5. Urdl WW, Apter DD, Alperstein AA, et al. Contraceptive efficacy, compliance and beyond: factors related to satisfaction with once-weekly transdermal compared with oral contraception. Eur J Obstet Gynecol Reprod Biol. 2005;121(2):202-210.

6. Abrams LS, Skee DM, Natarajan J, et al. Pharmacokinetics of norelgestromin and ethinyl estradiol delivered by a contraceptive patch (Ortho Evra/Evra) under conditions of heat, humidity, and exercise. J Clin Pharmacol. 2001;41(12):1301-1309.

7. Bitzer J, Simon JA. Current issues and available options in combined hormonal contraception. Contraception. 2011;84(4):342-356.

8. Vrablik MM, Fait TT, Kovar JJ, Poledne RR, Ceska RR. Oral but not transdermal estrogen replacement therapy changes the composition of plasma lipoproteins. Metabolism. 2008;57(8):1088-1092.

9. Sitruk-Ware R, Plu-Bureau G, Menard J, et al. Effects of oral and transvaginal ethinyl estradiol on hemostatic factors and hepatic proteins in a randomized, crossover study. J Clin Endocrinol Metab. 2007;92(6): 2074-2079.

10. van den Heuvel MW, van Bragt AJ, Alnabawy AK, Kaptein MC. Comparison of ethinylestradiol pharmacokinetics in three hormonal contraceptive formulations: the vaginal ring, the transdermal patch and an oral contraceptive. Contraception. 2005;72(3):168-174.

11. Practice Committee of American Society for Reproductive Medicine. Hormonal contraception: recent advances and controversies. Fertil Steril. 2008;90(Suppl 5):S103-S113.

12. Cole JA, Norman H, Doherty M, Walker AM. Venous thromboembolism, myocardial infarction, and stroke among transdermal contraceptive system users. Obstet Gynecol. 2007;109(2 Pt 1):339-346.

13. Lidegaard Ø, Løkkegaard E, Jensen A, Skovlund CW, Keiding N. Thrombotic stroke and myocardial infarction with hormonal contraception. N Engl J Med. 2012;366(24):2257-2266.

14. Jick SS, Kaye JA, Russmann S, Jick H. Risk of nonfatal venous thromboembolism in women using a contraceptive transdermal patch and oral contraceptives containing norgestimate and 35 microg of ethinyl estradiol. Contraception. 2006;73(3):223-228.
15. Sidney S, Cheetham TC, Connell FA, et al. Recent combined hormonal contraceptives (CHCs) and the risk of thromboembolism and other cardiovascular events in new users. Contraception. 2013;87(1): 93-100.

16. Sibai BM, Odlind V, Meador ML, Shangold GA, Fisher AC, Creasy GW. A comparative and pooled analysis of the safety and tolerability of the contraceptive patch (Ortho Evra/Evra). Fertil Steril. 2002; 77(2 Suppl 2):S19-S26.

17. O'Connell K, Burkman RT. The transdermal contraceptive patch: an updated review of the literature. Clin Obstet Gynecol. 2007;50(4): 918-926.

18. Archer DF, Stanczyk FZ, Rubin A, Foegh M. Pharmacokinetics and adhesion of the Agile transdermal contraceptive patch (AG200-15) during daily exposure to external conditions of heat, humidity and exercise. Contraception. 2013;87(2):212-219.

19. Nappi RE, Terreno E, Sances G, et al. Effect of a contraceptive pill containing estradiol valerate and dienogest (E2V/DNG) in women with menstrually-related migraine (MRM). Contraception. 2013;88(3): 369-375.

20. Massaro M, Di Carlo C, Gargano V, Formisano C, Bifulco G, Nappi C. Effects of the contraceptive patch and the vaginal ring on bone metabolism and bone mineral density: a prospective, controlled, randomized study. Contraception. 2010;81(3):209-214.

21. Harel ZZ, Riggs SS, Vaz RR, Flanagan PP, Harel DD, Machan JTJ. Bone accretion in adolescents using the combined estrogen and progestin transdermal contraceptive method Ortho Evra: a pilot study. J Pediatr Adolesc Gynecol. 2010;23(1):23-31.

22. Foegh M, Archer DF, Stanczyk FZ, Rubin A, Mishell DR. Ovarian activity in obese and nonobese women treated with three transdermal contraceptive patches delivering three different doses of ethinyl estradiol and levonorgestrel. Contraception. 2013;87(2):201-211.

23. Zieman M, Guillebaud J, Weisberg E, Shangold GA, FisherAC, Creasy GW. Contraceptive efficacy and cycle control with the Ortho Evra/Evra transdermal system: the analysis of pooled data. Fertil Steril. 2002; 77(2 Suppl 2):S13-S18.

24. Bitzer J, Gemzell-Danielsson K, Roumen F, Marintcheva-Petrova M, van Bakel B, Oddens BJ. The CHOICE study: effect of counselling on the selection of combined hormonal contraceptive methods in 11 countries. Eur J Contracept Reprod Health Care. 2012;17(1):65-78.

25. Jakimiuk AJ, Crosignani PG, Chernev T, et al. High levels of women's satisfaction and compliance with transdermal contraception: results from a European multinational, 6-month study. Gynecol Endocrinol. 2011;27(10):849-856.

26. Stewart FH, Kaunitz AM, Laguardia KD, Karvois DL, Fisher AC, Friedman AJ. Extended use of transdermal norelgestromin/ethinyl estradiol: a randomized trial. Obstet Gynecol. 2005;105(6): 1389-1396.

27. Heger-Mahn D, Warlimont C, Faustmann T, Gerlinger C, Klipping C. Combined ethinylestradiol/gestodene contraceptive patch: two-center, open-label study of ovulation inhibition, acceptability and safety over two cycles in female volunteers. Eur J Contracept Reprod Health Care. 2004;9(3):173-181.

28. Junge W, Heger-Mahn D, Trummer D, Merz M. Investigation of the hemostatic effect of a transdermal patch containing $0.55 \mathrm{mg}$ ethinyl estradiol and $2.1 \mathrm{mg}$ gestodene compared with a monophasic oral contraceptive containing $0.03 \mathrm{mg}$ ethinyl estradiol and $0.15 \mathrm{mg}$ levonorgestrel: an open-label, randomized, crossover study. Drugs R D. 2013;13(3): 223-233.

29. Gao Y, Liang J, Liu J, Xiao Y. Double-layer weekly sustained release transdermal patch containing gestodene and ethinylestradiol. Int $J$ Pharm. 2009;377(1-2):128-134. 
Open Access Journal of Contraception

Dovepress

\section{Publish your work in this journal}

Open Access Journal of Contraception is an international, peerreviewed, open access, online journal, publishing original research, reports, reviews and commentaries on all areas of contraception. In addition to clinical research, demographics and health-related aspects, the journal welcomes new findings in animal and preclinical studies

relating to understanding the biological mechanisms and practical development of new contraceptive agents. The manuscript management system is completely online and includes a very quick and fair peer-review system. Visit http://www.dovepress.com/testimonials.php to read real quotes from published authors.

Submit your manuscript here: http://www.dovepress.com/open-access-journal-of-contraception-journal 